\title{
Fotogrametri tekniğine dayalı üç boyutlu baskı uygulaması: Leblebi Anıtı örneği
}

\author{
Ahmet Uslu*1 (D) \\ ${ }^{1}$ Kütahya Dumlupınar Üniversitesi, Tavşanlı Meslek Yüksekokulu, Mimarlık ve Şehir Planlama Bölümü, Kütahya, Türkiye
}

\author{
Anahtar Kelimeler \\ Fotogrametri \\ 3B Modelleme \\ 3B Baskl \\ Anit
}

\begin{abstract}
ÖZ
Üç boyutlu (3B) baskı teknolojisi, çağımızın en önemli teknolojilerinden biridir. 3B baskı, dijital bir dosyadan 3B nesneler üretme yöntemidir. Nesnelerin 3B dijital modelleri fotogrametrik teknikler kullanılarak hızlı bir şekilde oluşturabilir ve dijital modeller eklemeli üretim ilkesine dayanan 3B baskı teknolojisi ile yazdırabilir. Bu çalışmada, bir anıtın gerçekliğe dayalı 3B dijital modelinden, baskısının üretilmesine yönelik yaklaşım sunulmaktadır. 3B dijital model üretmek için fotogrametri tekniği ve dijital modeli 3B baskı teknolojisi ile yazdırmak için eriyik yığma modelleme (EYM) üretim tekniği kullanılmıștır. Çalışmada tanımlanan yaklaşım, nesnelerin 2B görüntülerinden 3B katı baskı modeller üretmek için basit ve uygun maliyetli bir yöntem sağlamaktadır. Sonuç olarak, fotogrametri tekniğine dayalı 3B baskı teknolojilerinin geniş bir yelpazede yeni firsatlar sunduğu ve zenginleștirici deneyimler vaat ettiği düşünülmektedir.
\end{abstract}

\section{Three-dimensional printing application based on photogrammetry technique: The case study of Leblebi Monument}

\author{
Keywords \\ Photogrammetry \\ 3D Modeling \\ 3D Printing \\ Monument
}

\begin{abstract}
Three-dimensional (3D) printing technology is one of the most important technologies of our time. 3D printing is a method of generating 3D objects from a digital file. 3D digital models of objects can be quickly created using photogrammetric techniques and digital models can be printed using 3D printing technology based on the principle of additive manufacturing. In this study, the approach to producing the print of a monument from a reality-based 3D digital model is presented. Photogrammetry technique was used to produce 3D digital model and fused deposition modeling (FDM) production technique was used to print digital model with 3D printing technology. The approach described in the study provides a simple and costeffective method for producing 3D solid-printed models from 2D images of objects. As a result, it is thought that 3D printing technologies based on photogrammetry technique offer a wide range of new opportunities and promise enriching experiences.
\end{abstract}




\section{Giriș}

Dördüncü sanayi devrimi olarak tanımlanan Endüstri 4.0 süreci, imalat paradigmalarına daha uygun maliyetli daha sağlam ve verimli çözümler sağlamak için tasarlanmış yeni ve yenilikçi teknolojilerin gelişimi sayesinde hızla genişlemektedir (Prinsloo ve ark., 2019). $\mathrm{Bu}$ yeni teknolojilerin en öne çıkanlarından biri 3B baskıdır. 3B baskl, bilgisayar destekli bir tasarım programında oluşturulan sanal bir modelden bir kalıbın hızlı ve doğru bir şekilde prototiplenmesini sağlayan, projelerin çeşitli kullanımlar için doğrudan nihai ürünlere dönüştürülmesini sağlayan bir teknolojidir (Sears ve ark., 2016). Katmanlı bir üretim süreci olarak 3B baskı, üreticilerin karmaşı ürünleri geleneksel üretim yöntemlerinin gerektirdiği maliyetin çok altında elde edilmesini mümkün kılmıştır (Oropallo ve Piegl, 2016). Aynı zamanda 3B baskı teknolojileri, geleneksel üretim tekniklerinden çok daha yüksek bir üretim verimliliği sunmaktadır (Oropallo ve Piegl, 2016).

Son yıllarda 3B baskı teknolojilerinin kullanımı hızla artmaktadır. Son yıllarda geniş pazar ağı sayesinde düşük maliyetli masaüstü $3 \mathrm{~B}$ yazıcıların gelişiminde büyük ilerlemeler kaydedilmiş ve yeni kullanıcıların 3B baskı dünyasına girmesi hızlanmıştır (Balletti ve Ballarin, 2019). 3B baskı teknolojisi, gıda sektörü, tıp, diș hekimliği mimarlık, mühendislik, eğitim, endüstriyel tasarım ve üretim gibi birçok bilgisayar destekli imalat alanlarında yaygin olarak kullanılmaktadır (Balletti ve ark., 2017). Dokunsal arayüzler ve basılı kopyalar hem dokunsal hem de kinestetik geri bildirim sağlayabilir ve orijinal malzemelerin fiziksel özelliklerini simüle edebilir. Bununla birlikte kullanıcı, şekil ve rengin basit bir şekilde değerlendirilmesinin ötesine geçebilir ve nesnenin ağırlığını, yapısını ve dokusunu hissedebilir (Brewster, 2017).

Günümüzde bileșenlerin daha az maliyetli ve daha hızlı üretilmesi talebi ortaya çıkmıştır. Üretim ve çoğaltma sürecini desteklemek için yüksek çözünürlüklü 3B modellere ihtiyaç duyulmaktadır. $\mathrm{Bu}$ ihtiyacı karşılamada fotogrametri tekniği sıklıkla kullanılmaktadır (Balletti ve Ballarin, 2019). Fotogrametri teknolojisindeki son gelişmeler, 2B görüntülerden nispeten doğru 3B modeller üretmek için basit ve uygun maliyetli bir yöntem sağlamaktadır (Remondino ve El-Hakim, 2016). Fotogrametri tekniği arkeolojik alanlardan (Polat ve ark., 2020, Kaya ve ark., 2021), mimari eserlere (Uslu ve Uysal, 2021; Şenol ve ark., 2021) ve arkeolojik eserlere (Uslu ve Uysal, 2017; Uslu ve Uysal, 2020) kadar çok çeşitli farklı yapıların 3B dijitalleştirilmesinde yaygın olarak kullanılmaktadır. Fotogrametri tekniği ile nesnelerin 3B modelleri hızlı bir şekilde oluşturabilir ve dijital bir 3B model eklemeli üretim ilkesine dayanan 3B baskı teknolojisi ile 3B katı bir nesne biçiminde yazdırabilir (Yang ve ark., 2021). Bu iki teknoloji, sanal (dijital) ve gerçeklik arasındaki karşılıklı dönüşümü gerçekleștirir ve çeşitli alanlarda uygulama açısından geniş bir yelpazede yeni olanaklar sunar (Yang ve ark., 2021).

Literatür taraması neticesinde fotogrametri ve 3B baskı teknolojisi sinerjisini içeren çalışmaların ana temaları aşağıda özetlenmiştir. Themistocleous ve ark., (2015), çalışmalarında Kıbrıs'taki Asinou Kilisesi'nin yüksek çözünürlüklü İHA görüntülerini kullanarak fotogrametri tekniği ile eserin 3B dijital modelini oluşturmuşlardır. 3B yazıcıda beyaz renkli polilaktik asit (PLA) malzeme kullanarak 3B dijital modelin baskısını gerçekleştirmişlerdir. Musul Projesi'nde (URL 1) IŞSiD tarafindan tahrip edilen dört adet antik eserin, kitle kaynaklı fotoğrafları kullanılarak fotogrametri tekniği ile 3B dijital modelleri oluşturulmuş, tahrip edilen parçalarının 3B basklları ile eserlerin restorasyonu gerçekleştirilmiștir. D'Agnano ve ark. (2015), görme engelli bireylerin nesneleri deneyimleyebilmelerine yardımcı olmak için dokunma ve işitmeyi birleştiren akıllı giyilebilir bir cihaz tasarlamışlardır. Fotogrametri tekniği ve 3B baskı teknolojisi kullanılarak İsola'daki San Michele Kilisesi'nin 3B dokunsal baskısını üretmiş̧lerdir. 3B baskı model dokunma ve işitmeyi birleştiren cihazlarla donatılarak görme engelli bireyler için erişilebilir hale getirilmiştir. Themistocleous ve ark. (2016), çalışmalarında görme engelli bireyler için öğretim faaliyetlerinde dokunsal eğitim aracı olarak kullanılmak üzere Limasol şehrinin güney batısında yer alan, Curium arkeolojik amfi tiyatro alanının 3B baskısını gerçekleștirmişlerdir. Araştırmacılar öncelikle İHA'dan elde edilen 331 adet fotoğrafı kullanarak hava fotogrametrisi tekniği ile antik tiyatronun 3B modelini oluşturmuşlar ve 3B yazıcı aracıllğıyla antik tiyatronun baskısını gerçekleştirmişlerdir. Scianna ve Di Filippo (2019), araştırmalarında görme engelli bireylerin kültürel mirasa erişimini artırmak amacıyla 3B modellerin özellikleri ile ilgili standartların ve kılavuzların tanımlanmasına odaklanmışlardır. Çalışmada Palermo kentinde yer alan San Sebastiano kilisinin 3B modeli lazer tarayıcı kullanılarak elde edilmiş, model farklı temsil ölçeklerinde, farklı çözünürlük ve ayrıntı düzeylerinde $3 \mathrm{~B}$ yazıcıda PLA malzeme ile çoğaltılmıştır. İsmail ve ark. (2020), araştırmalarında fotogrametri ve 3B baskı tekniği ile uygun fiyatlı ve daha hızlı transradyal protez soket üretimi gerçekleștirmişlerdir. Araştırmacılar geleneksel döküm ve 3B baskı yöntemleriyle üretilen soketleri kullanılabilirlik testi ile karșılaștırmıșlardır. Çalıșmada fotogrametri ve 3B baskı teknolojisi kullanılarak edilen üretimin geleneksel üretim tekniklerinin yerini alabileceği doğrulanmıștır. Isaacson ve ark. (2020), 3B cerrahi anatomi modellerinde kullanılmak üzere, dirsek açık redüksiyon ve iç fiksasyonun etkileşimli 3B modellenmesi için hızlı ve uygun maliyetli bir çözüm olarak fotogrametri tekniği ve 3B baskı teknolojisini kullanmışlardır. Salazar-Gamarra ve ark. (2016), düşük maliyetli ekipman ile maksillofasiyal defektleri olan hastaların dijital yüz ölçülerini almak için bir yöntem olarak fotogrametri tekniğini kullanmışlardır. Elde ettikleri dijital modeli klinik çalışmalarda yüz protezi olarak kullanmak üzere 3B baskı teknolojisi ile yazdırmışlardır. Lima ve ark. (2019), veteriner hekimlikte ortopedik teknikler eğitimi amacıla köpek türlerinin kemik biyomodellerinin üretimi için fotogrametri ve 3B baskl teknolojisinin kullanım potansiyelini araştırmışlardır. Bonora ve ark. (2021), İtalya, Pistoia, San Giovanni Vaftizhanesi'ndeki orijinal yerlerinden kaldırılmış birkaç mermer heykelin kopyalarının gerçekleștirilmesine yönelik bir çalıșma gerçekleştirmişlerdir. Gerçekliğe dayalı 3B modeller 
üretmek için fotogrametri tekniğinden ve 3B baskıları için EYM üretim tekniğinden faydalanmışlardır.

$\mathrm{Bu}$ çalışmada, 3B dijital model oluşturmak ve dijital modelin 3B yazıcı ile baskını gerçekleştirmek amacıyla bir yaklaşım sunulmuştur. İş akışı Kütahya ili, Tavşanlı ilçesinde yer alan Leblebi Anıtına uygulanmıştır. Öncelikle anıtın 3B dijital modeli fotogrametri tekniği ile oluşturulmuştur. Daha sonra oluşturulan 3B dijital modelin, 3B yazıcıda 1:40 ölçeğinde 50 mikron katman kalınlığı, \% 50 doluluk oranı ve 71 gram beyaz renkli PLA (Polilaktik Asit) malzeme kullanılarak 4 saat 27 dakikada, $10 \mathrm{~cm}$ x $10.16 \mathrm{~cm} \quad \mathrm{x} 8.66 \mathrm{~cm} \quad(\mathrm{G}, \mathrm{D}, \mathrm{Y})$ boyutlarında baskısı gerçekleştirilmiştir.

\section{Materyal ve yöntem}

\section{1. Çalıșma alanı}

Çalışmada Kütahya ili, Tavşanlı ilçesinde yer alan Leblebi Anıtı model olarak seçilmiştir (Şekil 1).

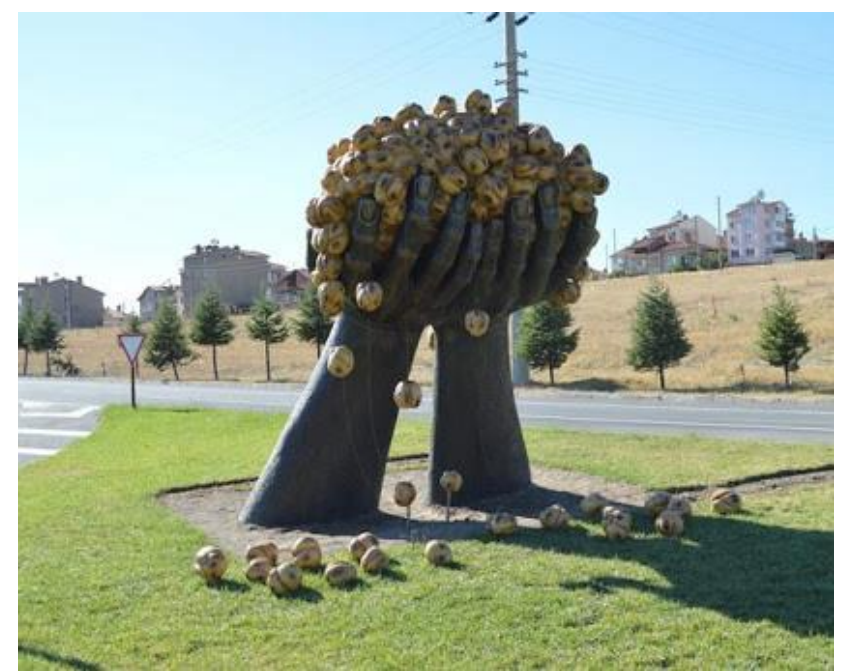

Şekil 1. Leblebi Anıtı

Leblebi Anıtı, kömür ve leblebi diyarı olarak bilinen ilçeye, yöresel şehir anıt olarak 2016 yılında Tavşanlı Belediyesi tarafindan yaptırılmıștır. Anıt, toprak zemin içinden çıkan bir madencinin avuçları arasından taşan kavrulmuş leblebileri tasvir etmektedir. Leblebi Anıtı, $4.03 \mathrm{~m}$ genişliğe, $4.09 \mathrm{~m}$ derinliğe ve $3.49 \mathrm{~m}$ yüksekliğe sahiptir (URL 2). Bu çalışmada Leblebi Anıtının 1:40 oranında baskısı gerçekleştirilmiştir.

\section{2. Çalışmanın materyalleri}

Çalışmada, Leblebi Anıtının fotoğraflarının çekimi için Samsung ST150 dijital fotoğraf makinesi, anıt üzerinde belirlenen kontrol noktalarına ait koordinat değerlerinin ölçümü için Spectra Focus 6 reflektörsüz totalstation cihazl, fotogrametrik değerlendirme ve $3 \mathrm{~B}$ modelleme işlemleri için lisanslı Agisoft PhotoScan yazılımı, 3B baskı öncesi gerekli kontrollerin ve düzenlemelerin yapılması için Autodesk Meshmixer yazılımı, 3B baskı parametrelerinin tanımlanması için Ultimaker Cura yazılımı ve son olarak 3B baskı işlemi için Prusa i3 3B yazıcı kullanılmıştır (Şekil 2).
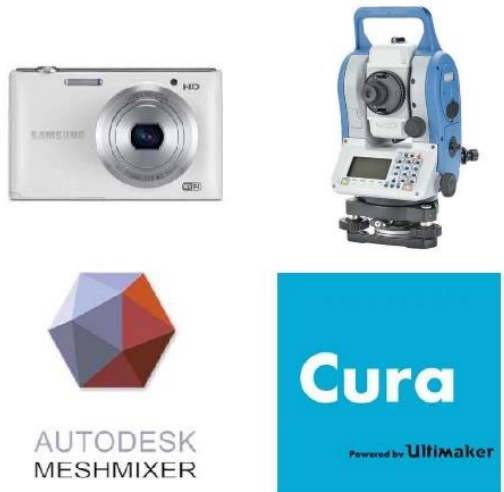

Şekil 2. Çalışmanın materyalleri

Tablo 1'de fotoğraf makinesine ait teknik özellikler gösterilmektedir.

Tablo 1. Samsung ST150 dijital fotoğraf makinesinin teknik özellikleri (URL 3).

\begin{tabular}{cc}
\hline Özellik & Değer \\
\hline Mega piksel & $16.2 \mathrm{MP}$ \\
Maksimum Görüntü & $4608 \times 3456$ \\
Çözünürlüğü & $112 \mathrm{~g}$ \\
Ağırlık & \\
Boyut & CCD \\
Sensör Tipi & $1 / 2.3 ”(\sim 6.16 \times 4.62 \mathrm{~mm})$ \\
Sensör Parametreleri & $6.16 \times 4.62 \mathrm{~mm}$ \\
Sensör Boyutu & $56.79 \mathrm{MP} / \mathrm{cm}^{2}$ \\
Piksel Yoğunluğu & $1.33 \mu \mathrm{m}$ \\
Piksel Kenar Uzunluğu &
\end{tabular}

Fotoğraf makinesinin kalibrasyon değerleri Tablo 2'de gösterilmektedir.

Tablo 2. Samsung ST150 dijital fotoğraf makinesinin kalibrasyon değerleri

\begin{tabular}{ccc}
\hline Parametre & & Değer \\
\hline Odak uzaklığı & $\mathrm{fx}$ & 4.9734 \\
Odak uzaklığı & $\mathrm{fy}$ & 4.9734 \\
Resim Ana Noktası Koordinatları & $\mathrm{cx}$ & 3.1007 \\
Resim Ana Noktası Koordinatları & $\mathrm{cy}$ & 2.4131 \\
Radyal & $\mathrm{K} 1$ & $4.498 \mathrm{e}-004$ \\
Radyal & $\mathrm{K} 2$ & $-2.612 \mathrm{e}-005$ \\
Radyal & $\mathrm{K} 3$ & $0.000 \mathrm{e}+000$ \\
Teğetsel & $\mathrm{P} 1$ & $1.655 \mathrm{e}-003$ \\
Teğetsel & $\mathrm{P} 2$ & $-2.337-004$ \\
\hline
\end{tabular}

\subsection{Yöntem}

Çalışmanın yöntemi için konuyla ilgili olarak geniş bir literatür taraması sonucu elde edilen kaynaklardan ve belgelerden yararlanılmıştır. Fotogrametri tekniğine dayalı 3B baskı üretimi uygulaması arazi ve büro çalışmalarından oluşmaktadır. Arazi çalışmaları; resim koordinat sisteminden arazi koordinat sistemine dönüşümün sağlanması amacıyla obje üzerinde belirlenen kontrol noktalarına ait koordinat değerlerinin (X, Y, Z) ölçümü ve objenin tüm yönlerden fotoğraflarının çekilmesi işlemlerinden oluşmaktadır. Büro çalışmaları ise fotoğrafların ve jeodezik ölçüm sonrası elde edilen 
koordinat değerlerinin bilgisayara aktarılması, fotogrametrik değerlendirme ve 3B modelleme işlemleri, elde edilen $3 \mathrm{~B}$ dijital modelin optimize edilerek baskı öncesi hazır hale getirilmesi ve son olarak baskı parametreleri tanımlanarak modelin 3B baskı üretiminin gerçekleştirilmesi aşamalarından oluşmaktadır. Şekil 3' te çalışmanın yöntemi için genel bir çerçeve sunulmuştur.

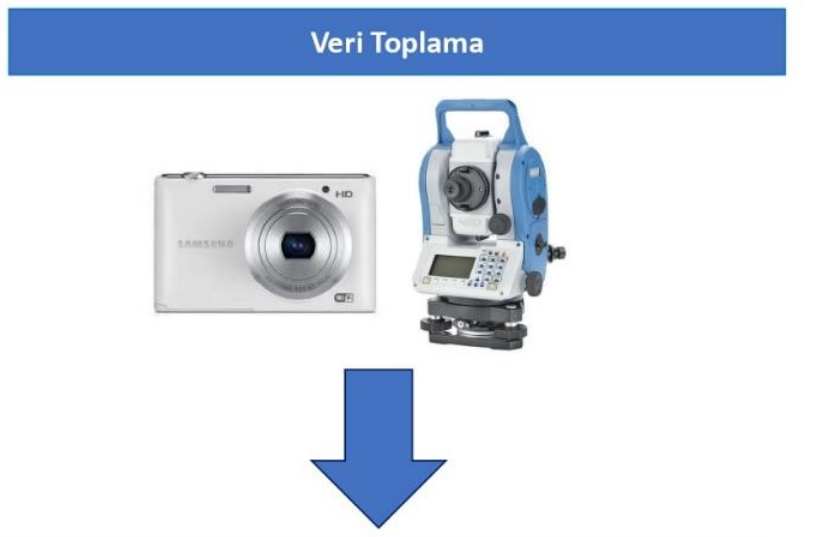

Fotogrametrik Değerlendirme ve 3B Modelleme
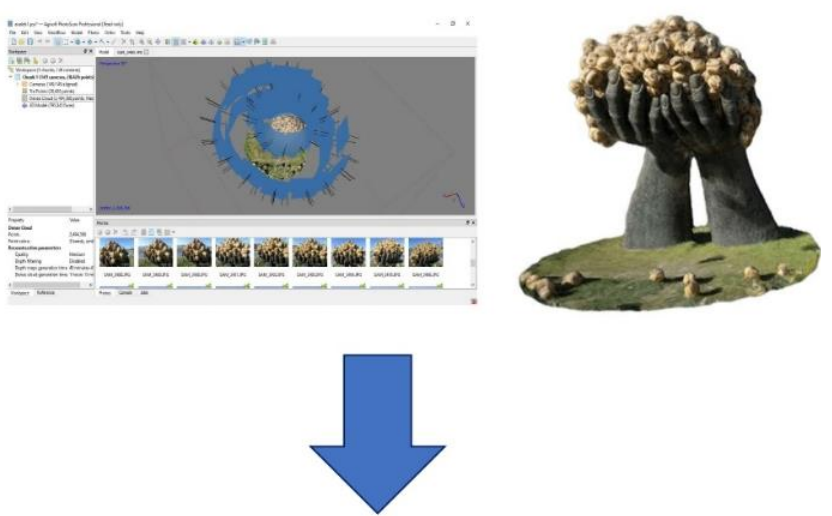

\section{B Baskı}
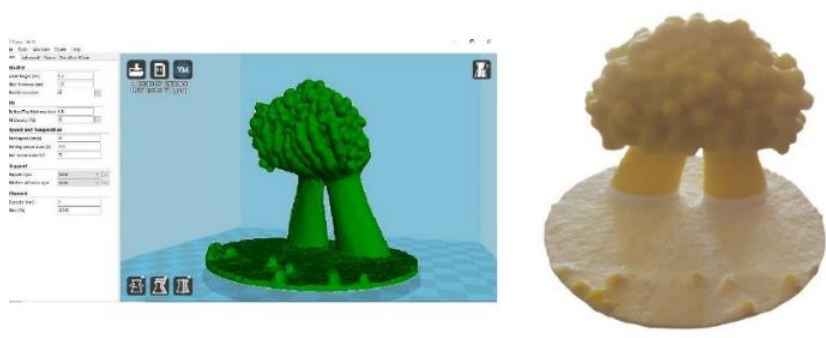

Şekil 3. Çalışmanın yöntemi

\section{Bulgular}

\subsection{Veri toplama}

Veri toplama aşamasında öncelikli olarak koordinatlandırma ve konum doğruluğunun irdelenmesi ișlemlerinde kullanmak amacıyla Leblebi Anıtının üzerinde 38 adet kontrol noktası işaretlenmiştir. Kontrol noktaları belirlenirken noktaların tüm fotoğraflarda görünür ve seçilebilir olmasına dikkat edilmiştir. Kontrol noktalarından 28 tanesi 3B dijital modelin koordinatlandırılmasında, 10 tanesi de konum doğruluğunun analizi işleminde kullanılmak üzere belirlenmiştir. Daha sonra Leblebi Anıtını tüm cepheleri ile kapsayan lokal koordinat sisteminde kapalı poligon güzergâhı olușturulmuștur. Kontrol noktalarının ölçümü için Spectra Focus 6 reflektörsüz totalstation cihazı kullanılmıştır. Sonraki adımda Samsung ST150 dijital fotoğraf makinesi ile konvergent çekim esaslarına göre anıtın 148 adet fotoğrafı çekilmiştir. Fotoğraf çekimi yapılırken kontrol noktalarının fotoğraflarda görünür olmasına dikkat edilmiştir.

\subsection{Fotogrametrik değerlendirme ve $3 B$ modelleme}

Fotogrametrik değerlendirme ve 3B model oluşturma işlemleri Agisoft PhotoScan yazlımında gerçekleştirilmiştir. Fotoğraf veri seti olarak 148 adet fotoğraf kullanılmıştır. Öncelikle yöneltme işlemi gerçekleştirilmiştir (Şekil 4).

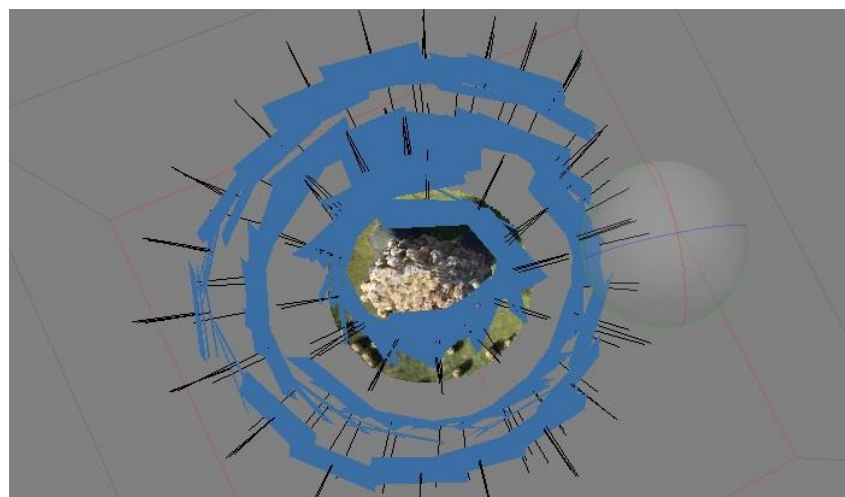

Şekil 4. Fotoğrafların yöneltilmesi

148 adet fotoğrafin tamamı, 28,426 adet bağlantı noktası kullanılarak otomatik olarak hizalanmıştır. Daha sonra arazi çalışmaları sırasında koordinat değerleri ölçülen 28 adet kontrol noktası nokta atmak suretiyle işaretlenmiştir (Şekil 5).

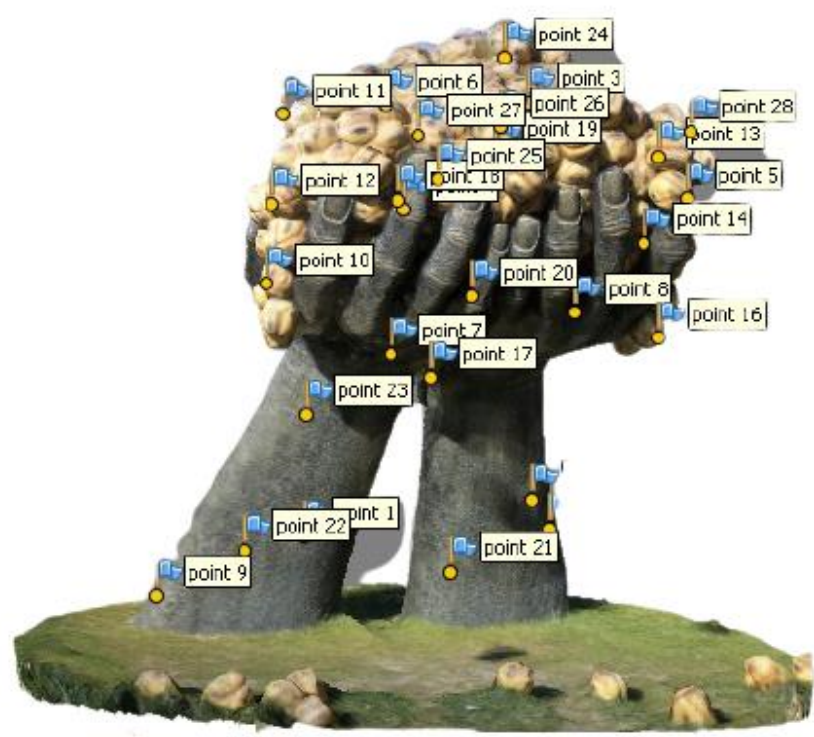

Şekil 5. Kontrol noktalarının işaretlenmesi

Kontrol noktaları ile birlikte anıtın sırasıyla 3B yoğun nokta bulutu $(2,494,366$ adet) (Şekil 6), 3B yüzeyler (800,000 yüzey) ve 3B dokulu modeli oluşturulmuştur (Şekil 7). 


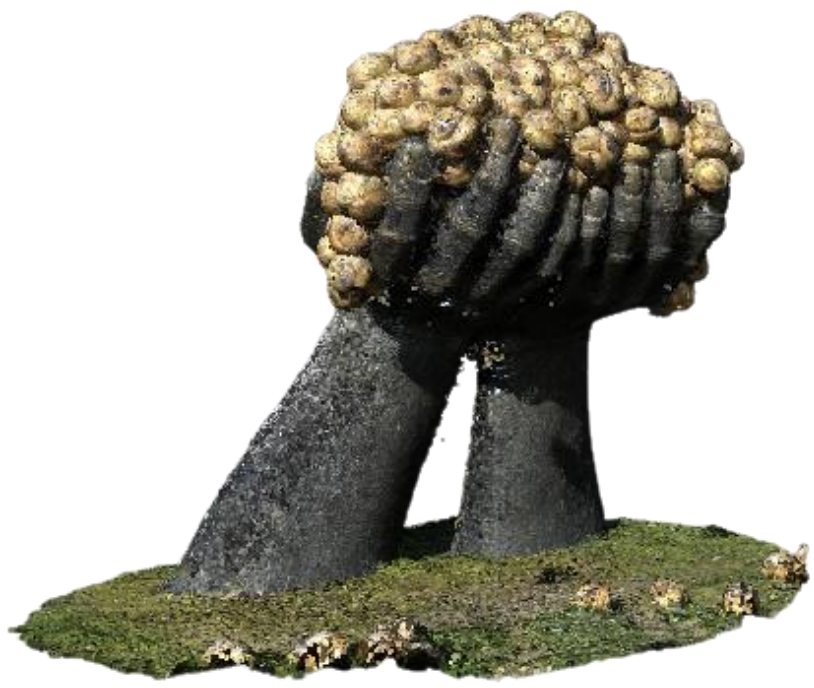

Şekil 6. Leblebi Anıtının 3B yoğun nokta bulutu

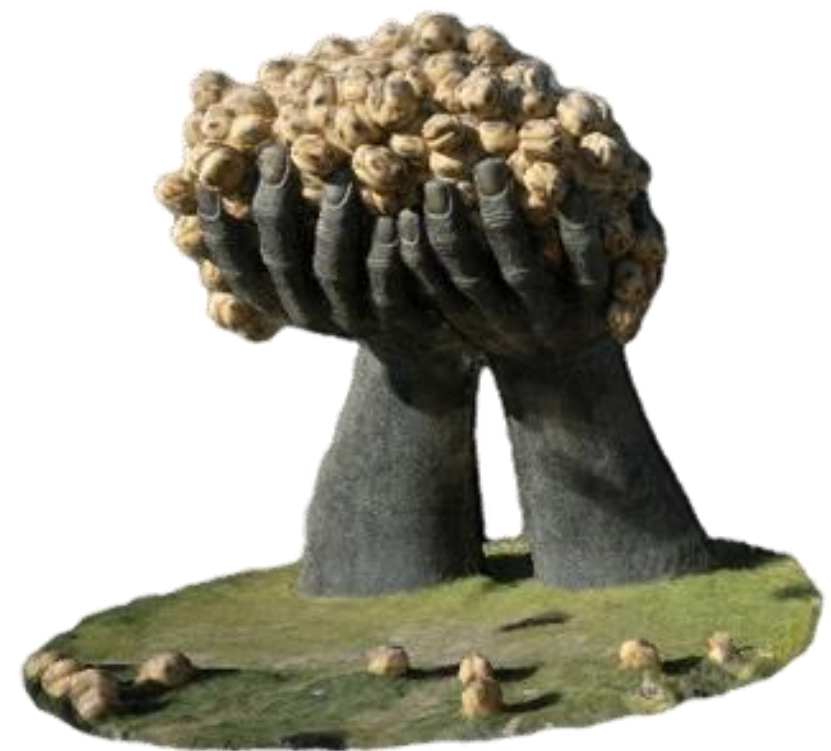

Şekil 7. Leblebi Anıtının 3B katı modeli

Son olarak, 3B dijital model Autodesk Meshmixer yazılımında işlenmek üzere ".obj” uzantılı model dosyası olarak dişa aktarılmıştır.

\subsection{Doğruluk analizi}

3B modelin hatasını ve başarısını irdelemek amaciyla doğruluk analizi gerçekleştirilmiştir. Doğruluk analizi için totalstation cihazı ile elde edilen arazi koordinatları ve görüntü üzerinden alınan test verileri değerlendirilmiştir. Koordinatlandırma işleminde kullanılmayan, homojen dağılımlı 10 adet kontrol noktası test verisi olarak seçilmiştir. Arazi çalışmasında ölçülen koordinatlar kesin koordinat olarak kabul edilmiştir. Aynı kontrol noktaları yazılımda değerlendirilip resim koordinat değerlerinden farkları alınarak, 10 adet kontrol noktasının $\mathrm{x}, \mathrm{y}, \mathrm{z}$ yönündeki karesel ortalama hataları hesaplanmıştır. 3B modelin konumsal doğruluğunun irdelenmesine yönelik yapılan araştırmaya ilişkin değerler Tablo 3' te gösterilmektedir.
Tablo 3. 3B modelin doğruluk analizi sonuçları.

\begin{tabular}{|c|c|c|c|}
\hline \multirow[b]{2}{*}{ NN } & \multicolumn{3}{|c|}{ Vi Farklar (mm) } \\
\hline & $\mathbf{V x}$ & Vy & $\mathbf{V z}$ \\
\hline 3 & -7 & 15 & 12 \\
\hline 8 & 12 & -18 & 10 \\
\hline 12 & 6 & 13 & 11 \\
\hline 17 & -9 & -10 & -8 \\
\hline 21 & -12 & 14 & -7 \\
\hline 24 & 14 & 6 & -9 \\
\hline 26 & -10 & -5 & 12 \\
\hline 32 & 17 & 8 & 13 \\
\hline 35 & 6 & -11 & 9 \\
\hline 37 & -16 & 14 & -8 \\
\hline $\mathbf{m}$ & 12.2 & 12.7 & 10.6 \\
\hline mxyz & & 20.6 & \\
\hline
\end{tabular}

Doğruluk analizi araştırması sonrası 3B modelin konum hassasiyeti $\pm 2.06 \mathrm{~cm}$ olarak bulunmuştur.

\subsection{B baskı uygulaması}

3B baskl öncesi gerekli kontrollerin ve düzenlemelerin yapılması için fotogrametrik değerlendirme sonucu elde edilen, 3B modele ilişkin “.obj" uzantılı dosya Autodesk Meshmixer programına aktarılmıştır (Şekil 8).

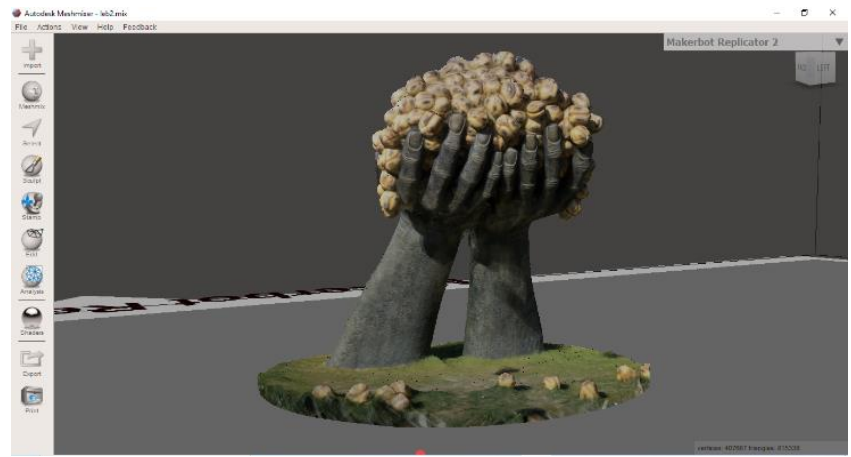

Şekil 8. Autodesk Meshmixer programında 3B baskı öncesi hazırlık işlemleri

Autodesk Meshmixer yazılımında Inspector aracl kullanılarak 3B model yüzeyi üzerinde boşluklar tespit edilmiştir. Pürüzsüz dolgu işlemi ile tespit edilen küçük boşluklar doldurularak model baskı işlemi öncesi hatasız hale getirilmiş ve ".stl" uzantılı dosya formatında dışarı aktarılmıştır. Bu işlemlerin ardından ".stl” uzantılı model dosyası 3B yazıcı programına (Ultimaker Cura) çağrılmış, yazdırma parametreleri tanımlanmış ve model yazdırma alanında uygun pozisyonda konumlandırılmıştır (Şekil 9).

Yazdırma ișlemi Prusa i3 3B yazıcı aracılı̆̆ıla 1:40 ölçeğinde, $10 \mathrm{~cm}$ x $10.16 \mathrm{~cm} \quad \mathrm{x} 8.66 \mathrm{~cm} \quad(\mathrm{G}, \mathrm{D}, \mathrm{Y})$ ebatlarında, 50 mikron katman kalınlığı, \% 50 doluluk oranı ile 71 gram beyaz renkli PLA (Polilaktik Asit) malzeme kullanılarak 4 saat 27 dakikada gerçekleştirilmiştir. Yazdırma işlemi sonucunda imal edilen model Şekil 10'da görülmektedir. 


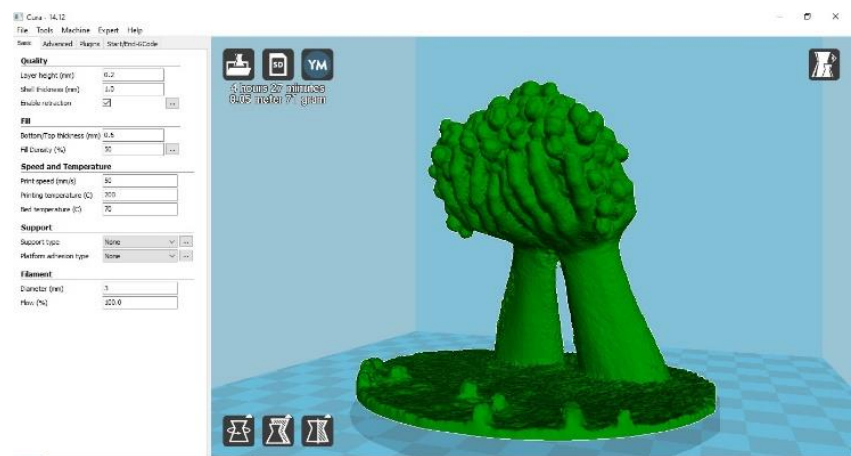

Şekil 9. Ultimaker Cura programında 3B baskı öncesi hazırlık işlemleri

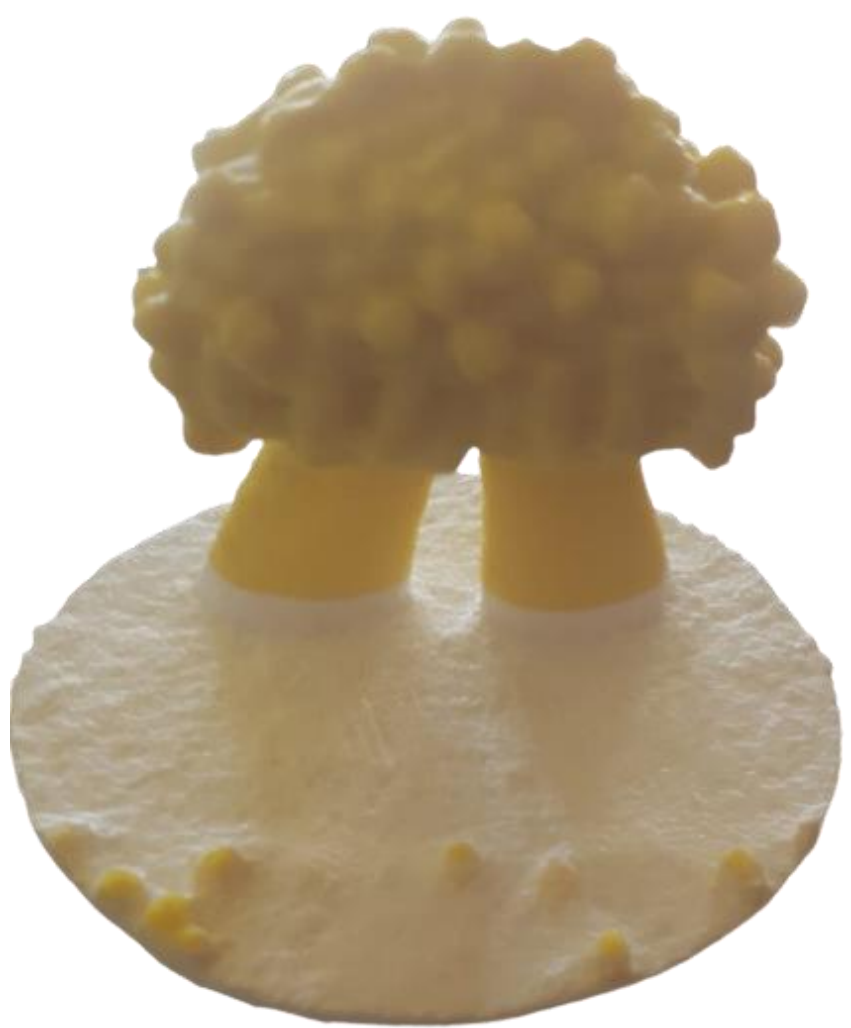

Şekil 10. Leblebi Anıtının 3B yazıcıdan üretilmiş çıktısı (1:40 ölçeğinde)

Anıtın üst bölümünün fotoğrafları eksik olduğu için fotogrametrik değerlendirme aşamasında yapının üst kısımda anlamlı nokta bulutu üretilememiș ve modelde boșluklar meydana gelmiștir. Buna bağlı olarak 3B baskının üst bölümlerinde detaylar kaybolmuştur. Anıtın diğer bölümleri incelendiğinde 1:40 ölçeğinde gürültü belirgin değil ve elde edilen detay seviyesinin bu boyutlar için yeterli olduğu söylenebilir.

\section{Sonuç ve öneriler}

Fotogrametri tekniğine dayalı 3B modeller, 3B baskl teknolojileri kullanılarak katı nesne biçiminde yazdırabilir. $\mathrm{Bu}$ iki teknoloji, sanal ve gerçeklik arasındaki karşılıklı dönüşümü sağlayarak çeşitli alanlarda potansiyel uygulama değerine sahiptir. $\mathrm{Bu}$ çalıșmada, bir anıtın fotogrametri tekniğine dayalı modelinin düşük maliyette üç boyutlu baskı üretimi amaçlanmıştır. Çalışma, fotogrametri tekniğine dayalı 3B baskı üretimi üzerine çalışan araştırmacılara ulaşmayı hedeflemekte, anıt eserlerin korunması ve yönetimi için referans olușturabilecek bir yaklașım sunmaktadır.

Çalıșmanın sonuçları, üretilen 3B baskı modelin șekil ve detaylarının korunduğunu, bu bağlamda $3 \mathrm{~B}$ yazıcıların, fotogrametrik teknikler kullanılarak oluşturulan 3B modellerin baskısını gerçekleştirmek için uygun bir araç olduğunu göstermektedir. Çalışma geleneksel döküm yöntemlerine nazaran fotogrametri tekniğine dayalı 3B baskıların doğruluk, hız, maliyet, verimlilik ve ürün çeşitliliği anlamında büyük avantajlar sağladığını ortaya koymuştur. Bununla birlikte fotogrametrik tekniklere dayalı 3B baskı teknolojilerinin, farklı disiplinlerin etkileşimi için geniş bir yelpazede yeni fursatlar sunduğu ve zenginleștirici deneyimler vaat ettiği düşünülmektedir.

Çalışmanın yöntemi ve sonuçları göz önünde bulundurularak geleceğe yönelik birtakım önerilerde bulunulmuştur:

- Fotogrametri tekniği ile 3B dijital modeller oluşturmak ve bunları 3B baskı yoluyla fiziksel olarak çoğaltmak, eğitim ve öğretim amaçlı faaliyetlerde önemli faydalar sağlayabilir.

- Fotogrametri tekniğine dayalı 3B baskı modeller, öğrenme güçlüğü çeken bireyler, çocuklar, yaşlılar ve görme engelli ziyaretçiler için kültürel mirasın erişilebilirliği açısından etkileşimli deneyimler sunabilir.

- Fotogrametri tekniği ve 3B baskı teknolojileri restorasyon uygulamalarında bir eserin eksik kısımlarını yeniden oluşturmak amacıyla kullanılabilir.

Gelecek çalışmalarda anıt eserlerin kullanıcı merkezli etkileşimli deneyimi ve keşfi için bütünsel bir uygulama olarak 3B baskı, artırılmış gerçeklik, sanal gerçeklik ve web tabanlı görselleştirme kombinasyonu gerçekleştirilecektir.

\section{Çatışma beyanı}

Herhangi bir çıkar çatışması bulunmamaktadır.

\section{Kaynakça}

Balletti C, Ballarin M \& Guerra F (2017). 3D printing: State of the art and future perspectives. Journal of Cultural Heritage, 26, 172-182.

Balletti C \& Ballarin M (2019). An application of integrated 3D technologies for replicas in cultural heritage. ISPRS International Journal of GeoInformation, 8(6), 285.

Bonora V, Tucci G, Meucci A \& Pagnini B (2021). Photogrammetry and 3D Printing for Marble Statues Replicas: Critical Issues and Assessment. Sustainability, 13(2), 680.

Brewster S (2017). The impact of haptic 'touching'technology on cultural applications. In Digital applications for cultural and heritage institutions (pp. 301-312).

D'Agnano F, Balletti C, Guerra F \& Vernier P (2015). Tooteko: A case study of augmented reality for an accessible cultural heritage. Digitization, 3D printing and sensors for an audio-tactile experience. The 
International Archives of Photogrammetry, Remote Sensing and Spatial Information Sciences, 40(5), 207.

Isaacson D S, Tanaka K S, Wang N K, Storelli D A \& Lattanza L L (2020). The Use of Photogrammetry for Interactive, Three-Dimensional Modeling of an Open Reduction and Internal Fixation of the Elbow. JAAOS Global Research \& Reviews, 4(11), e20.

Ismail $\mathrm{R}$, Taqriban $\mathrm{R} B$, Ariyanto $\mathrm{M}$, Atmaja $\mathrm{A} T$, Caesarendra W, Glowacz A, ... \& Glowacz W (2020). Affordable and faster transradial prosthetic socket production using photogrammetry and 3D printing. Electronics, 9(9), 1456.

Kaya Y, Polat N, Şenol H İ, Memduhoğlu A \& Ulukavak M (2021). Arkeolojik kalıntıların belgelenmesinde yersel ve İHA fotogrametrisinin birlikte kullanımı. Türkiye Fotogrametri Dergisi, 3 (1), 9-14.

Lima L F S D, Barros A J B P D, Martini A D C, Stocco M B, Kuczmarski A H \& Souza R L D (2019). Photogrammetry and 3D prototyping: A low-cost resource for training in veterinary orthopedics. Ciência Rural, 49.

Oropallo W \& Piegl L A (2016). Ten challenges in 3D printing. Engineering with Computers, 32(1), 135148.

Polat N, Önal M, Ernst F B, Şenol H İ, Memduhoglu A, Mutlu S, Mutlu S İ, Budan M, Turgut M \& Kara H (2020). Harran Ören Yeri Arkeolojik Kazı Alanınındın Çıkarılan Bazı Küçük Arkeolojik Buluntuların Fotogrametrik Olarak 3B Modellenmesi. Türkiye Fotogrametri Dergisi, 2(2), 55-59

Prinsloo J, Sinha S \& von Solms B (2019). A review of industry 4.0 manufacturing process security risks. Applied Sciences, 9(23), 5105.

Remondino F \& El-Hakim S (2006). Image-based 3D modelling: a review. The photogrammetric record, 21(115), 269-291.

Salazar-Gamarra R, Seelaus R, da Silva J V L, da Silva A M \& Dib L L (2016). Monoscopic photogrammetry to obtain 3D models by a mobile device: a method for making facial prostheses. Journal of OtolaryngologyHead \& Neck Surgery, 45(1), 1-13.

Sears N A, Seshadri D R, Dhavalikar P S \& CosgriffHernandez E (2016). A review of three-dimensional printing in tissue engineering. Tissue Engineering Part B: Reviews, 22(4), 298-310.
Scianna A \& Di Filippo G (2019). Rapid prototyping for the extension of the accessibility to cultural heritage for blind people. In: The International Archives of the Photogrammetry, Remote Sensing and Spatial Information Sciences, Proceedings of the 27th CIPA International Symposium "Documenting the past for a better future”, 1-5 September 2019, Ávi-la, Spain, vol. XLII-2/W15, pp. 1077-1082.

Şenol H İ, Yiğit A Y, Kaya Y \& Ulvi A (2021). İHA ve yersel fotogrametrik veri füzyonu ile kültürel mirasın 3 boyutlu (3B) modelleme uygulaması: Kanlıdivane Örneği. Türkiye Fotogrametri Dergisi, 3 (1), 29-36.

Themistocleous K, Ioannides M, Agapiou A, Hadjimitsis D G (2015). A New Approach for Documenting Architectural Cultural Heritage: The Case Study Of Asinou Church In Cyprus, Proceedings of the International Conference on Sustainability in Architecture and Cultural Heritage, 11-12 December, Limassol, Cyprus.

Themistocleous, K, Agapiou A \& Hadjimitsis D G (2016). Experiencing cultural heritage sites using 3D modeling for the visually impaired. In EuroMediterranean Conference (pp. 171-177).

Uslu A \& Uysal M (2017). Arkeolojik Eserlerin Fotogrametri Yöntemi ile 3 Boyutlu Modellenmesi: Demeter Heykeli Örneği. Geomatik, 2(2), 60-65.

Uslu A \& Uysal M (2020). Kültürel Mirasın Etkileşimli Keşfi İçin Mobil Artırılmış Gerçeklik ve Web Tabanlı Görselleștirme Teknolojilerinin Kullanılması: Sfenks Heykeli Örneği. Afyon Kocatepe Üniversitesi Fen ve Mühendislik Bilimleri Dergisi, 20 (6), 1024-1031.

Uslu A \& Uysal M (2021). Kitle Kaynaklı Fotoğraflar Kullanılarak Kültürel Mirasın Üç Boyutlu Modellenmesi ve Web Tabanlı Görselleștirilmesi: Afrodisias- Tetrapylon Örneği. Afyon Kocatepe Üniversitesi Fen ve Mühendislik Bilimleri Dergisi, 21 (3), 632-639.

Yang J, Yan G \& Geng P (2021). Study on 3D printing based on UAV oblique photogrammetry. In IOP Conference Series: Earth and Environmental Science 676, 1, 012010. IOP Publishing.

URL 1. https://www.projectmosul.org, (10.07.2021).

URL 2. https://www.tavsanli.bel.tr/ (10.07.2021).

URL 3. https:// www.2cameraguys.com/ (10.07.2021). 